\title{
SUSCEPTIBILITY OF NEW ZEALAND WHEAT CULTIVARS TO SHARP EYESPOT
}

\author{
M.G. CROMEY, R.C. BUTLER, C.A. MUNRO and S.C. SHORTER \\ Crop \& Food Research, Private Bag 4704, Christchurch, New Zealand
}

Corresponding author: cromeym@crop.cri.nz

\begin{abstract}
The susceptibility of 12 New Zealand wheat cultivars to sharp eyespot (caused by Rhizoctonia cerealis) was examined in three autumn-sown field trials in the 2004-05 growing season. Moderate to high disease incidence was recorded in two of the trials, and low levels occurred in the third. While disease incidence was high in at least some plots of most cultivars, low incidence was recorded in all plots of two cultivars, and all but two plots of two other cultivars. These trials provide evidence that at least 2 of the 12 cultivars have useful levels of resistance to sharp eyespot, and that several cultivars are highly susceptible. Ranking of the more susceptible cultivars varied between locations. Further work is required to determine whether this is due to genetic interactions between hosts and pathogens or whether relative susceptibility of cultivars to sharp eyespot can be affected by environment.
\end{abstract}

\section{INTRODUCTION}

Sharp eyespot of wheat (Triticum aestivum), caused by Rhizoctonia cerealis van der Hoeven, is common in New Zealand wheat crops (Cromey et al. 2002). The disease was recorded in $43 \%$ of surveyed South Island wheat crops in the 1998/99 growing season, and incidence in infected crops ranged from 2 to $88 \%$ from 1996 to 2000 (Cromey et al. 2002). Severe sharp eyespot of mature tillers may result in small, shrivelled grain, lodging and premature ripening (Clarkson \& Cook 1983). While sharp eyespot is not a major yield-limiting disease of wheat in New Zealand, it can reduce yields considerably under local conditions conducive to its establishment, with losses in individual crops calculated as high as $18 \%$ (Cromey et al. 2002). Yield loss has been shown to be related to disease incidence, and was considered to be negligible when the incidence was below $10 \%$ (Cromey et al. 2002). In England and Wales, severe infection has been shown to reduce yields by an average of $26 \%$ (Clarkson \& Cook 1983).

There is little information on cultivar resistance to sharp eyespot (Wiese 1987). Use of resistant cultivars, or at least the avoidance of highly susceptible cultivars, may be useful strategies to minimise yield losses from sharp eyespot. Field experiments comparing commercial wheat cultivars where plots were inoculated with $R$. cerealis were carried out over a number of years in the late 1970s and early 1980s at the Plant Breeding Institute, Cambridge, England (Hollins \& Scott 1983b). Differences in sharp eyespot infection were found between cultivars in each year. While some cultivars were always relatively heavily or lightly infected, the ranking order of cultivars was not always consistent. Clulow \& Wale (1984) conducted a similar trial with some of the same cultivars and, while there were again significant differences between cultivars, there was some inconsistency with the results of Hollins \& Scott (1983b). More recently, cultivar resistance in wheat to sharp eyespot has been examined in China. Variation in resistance between cultivars was identified, with cultivars ranging from highly resistant to highly susceptible, although only $4-7 \%$ of all wheat lines tested, and as few as $1.7 \%$ commercial cultivars, were resistant (He et. Al 1998; Shi et al. 2000). 
The series of trials reported in this paper provide preliminary information on whether current New Zealand wheat cultivars differ in resistance to sharp eyespot. The possible need for artificial inoculation of future cultivar evaluation trials is evaluated.

\section{MATERIALS AND METHODS}

Assessments of sharp eyespot were carried out in three cultivar field trials. Two trials were located at Chertsey, Canterbury, at the Foundation for Arable Research (FAR) field site. These two trials were in adjacent blocks, one of which was irrigated. Both trials were sown on 22 April 2004 in randomised complete block designs with 4 replicates, and consisted of 12 wheat cultivars in plots each consisting of 9 rows, $8 \mathrm{~m}$ long. Sharp eyespot incidence in each plot was assessed in situ on 4 January 2005 at the soft dough stage of grain development. The percentage of tillers with distinct sharp eyespot lesions on leaf sheaths was assessed by counting tillers (infected and healthy) in $0.5 \mathrm{~m}$ lengths of row (avoiding the outer two rows) in each of four positions in each plot.

The third (irrigated) trial, sown on 20 May 2004, was located at the Crop \& Food Research farm at Lincoln, Canterbury. This trial consisted of three sub-trials, each with three replicates in a randomised complete block design. The trials consisted of 54 cultivars, but only the 12 cultivars that were in the Chertsey trials were assessed for sharp eyespot incidence. Each plot was two rows, $1 \mathrm{~m}$ long. Plots were assessed for sharp eyespot infection on 12-14 January 2005, at the mid dough stage of grain development.

All data from these assessments were analysed by ANOVA, using this primarily as an exploratory tool rather than an exact analysis. The results were checked against an equivalent non-parametric analysis (Friedman's non-parametric ANOVA) and were found to be consistent.

\section{RESULTS}

Sharp eyespot was detected at moderate to high levels in two of the three trials assessed (Table 1). These two trials had similar sharp eyespot incidence, with a mean of $8.8 \%$ of tillers infected at the May-sown Lincoln trial and 10.9\% tillers affected at the April-sown irrigated Chertsey trial. Incidence was low (mean of 1.2\%) in the April-sown dryland trial at Chertsey, which was adjacent to the irrigated Chertsey trial.

TABLE 1: Mean and median incidence of sharp eyespot on tillers of 12 wheat cultivars in three field trials.

\begin{tabular}{|c|c|c|c|c|c|c|}
\hline \multirow[b]{2}{*}{ Cultivar } & \multicolumn{3}{|c|}{$\begin{array}{l}\text { Mean \% tillers with sharp } \\
\text { eyespot }\end{array}$} & \multirow[b]{2}{*}{$\begin{array}{c}\text { Median \% } \\
\text { tillers with } \\
\text { sharp eyespot }{ }^{1}\end{array}$} & \multirow[b]{2}{*}{$\begin{array}{c}\% \text { plots with } \\
>15 \% \text { tillers }^{1} \\
\text { infected }^{1}\end{array}$} & \multirow{2}{*}{$\begin{array}{l}\text { \% plots } \\
\text { with } \\
>30 \% \\
\text { tillers } \\
\text { infected }^{1}\end{array}$} \\
\hline & Lincoln & $\begin{array}{l}\text { Chertsey } \\
\text { irrigated }\end{array}$ & $\begin{array}{l}\text { Chertsey } \\
\text { dryland }\end{array}$ & & & \\
\hline Regency & 0.3 & 0.6 & 0.0 & 0.0 & 0.0 & 0.0 \\
\hline Centaur & 2.9 & 4.7 & 2.1 & 2.8 & 0.0 & 0.0 \\
\hline Weston & 3.9 & 9.4 & 0.6 & 3.8 & 7.7 & 0.0 \\
\hline Solstice & 6.8 & 10.6 & 0.0 & 5.7 & 30.8 & 0.0 \\
\hline Pennant & 7.1 & 6.3 & 0.6 & 7.0 & 7.7 & 0.0 \\
\hline Macro & 8.5 & 4.4 & 1.6 & 2.6 & 15.4 & 0.0 \\
\hline Alberic & 8.7 & 20.9 & 3.8 & 7.7 & 30.8 & 23.1 \\
\hline Option & 9.3 & 5.6 & 2.2 & 5.0 & 30.8 & 0.0 \\
\hline Claire & 10.0 & 23.4 & 0.6 & 9.7 & 46.2 & 15.4 \\
\hline Tanker & 10.8 & 16.9 & 1.3 & 6.5 & 23.1 & 7.7 \\
\hline Savannah & 12.0 & 18.8 & 0.0 & 15.5 & 53.8 & 7.7 \\
\hline Equinox & 24.8 & 9.1 & 1.9 & 20.0 & 61.5 & 30.8 \\
\hline LSD $(\mathrm{P}<0.05)$ & 7.4 & 14.1 & 3.5 & & & \\
\hline (df) & (88) & (33) & (33) & & & \\
\hline
\end{tabular}

${ }^{1}$ Combined for the Lincoln and the Chertsey irrigated trials. 
There were significant differences $(\mathrm{P}<0.05)$ between cultivars in mean sharp eyespot incidence in all trials (Table 1). However, there was considerable variation in disease within trials, between plots of the same cultivar (Fig. 1), which may mask intermediate levels of disease resistance. In addition, cultivar ranking was not completely consistent between trials in different locations.

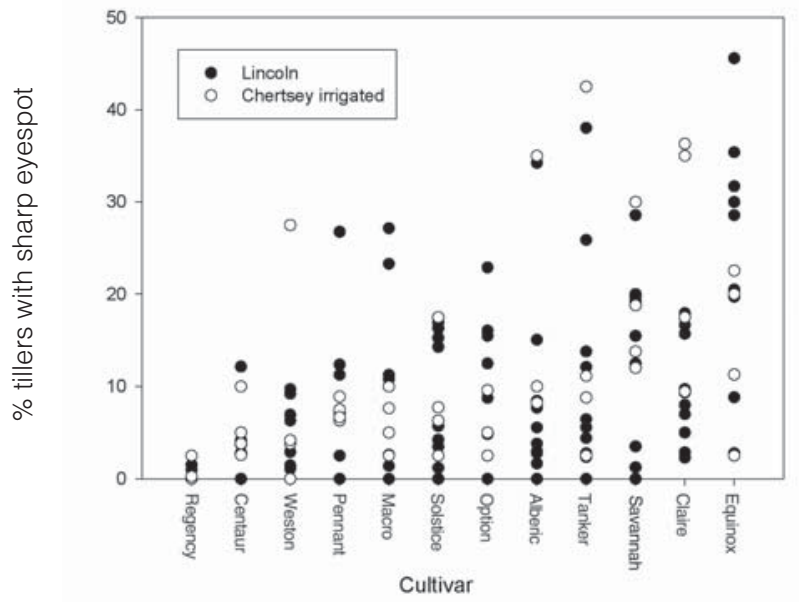

\section{FIGURE 1: Sharp eyespot incidence in plots in two wheat cultivar trials (Lincoln and irrigated Chertsey) in Canterbury in 2004/05. Data presented are values for individual plots.}

Two cultivars, Regency and Centaur, had low sharp eyespot incidence in all trials (median of 0.0 and $2.8 \%$ tillers infected respectively), and incidence of less than $15 \%$ in all plots. Two other cultivars, Weston and Pennant, had low to moderate disease levels in all trials, and had over 15\% infected tillers in only $8 \%$ of plots. Examination of data from neighbouring plots revealed no evidence that plots more heavily infected were affected by interplot interference. Of the other cultivars, Equinox and Savannah had over $15 \%$ tillers infected in over $50 \%$ of plots. However, sharp eyespot incidence in Equinox was very high at the Lincoln trial, but only moderate at the Chertsey irrigated trial. Relative disease incidence for two cultivars, Alberic and Claire, differed between trials. They each had moderate mean sharp eyespot incidence in the Lincoln trial, but high incidence in the irrigated Chertsey trial.

Sharp eyespot levels were too low in the dryland Chertsey trial to allow cultivars to be reliably compared, but the lack of the disease in Regency was consistent with the low incidence in the other trials. Incidence was highest in Alberic, which was the second most infected cultivar in the adjacent irrigated trial.

\section{DISCUSSION}

Results of these trials demonstrate differences in resistance to sharp eyespot between currently grown New Zealand wheat cultivars. There is good evidence that Regency and Centaur have useful levels of resistance, as the incidence of sharp eyespot in these cultivars was low in all plots. Four cultivars, Equinox, Savannah, Claire and Alberic, were highly susceptible to sharp eyespot, with a mean incidence of over $20 \%$ in at least 
one trial and median incidences across two trials of over 7.5\%. Tanker may also be at particular risk of sharp eyespot, with incidence of over 30\% in one plot.

Cultivar ranking was not always consistent between trials, as reported in studies in the United Kingdom (Hollins \& Scott 1983b; Clulow \& Wale 1984). This was particularly obvious in some of the more susceptible cultivars. For instance Equinox was by far the most heavily infected cultivar in the Lincoln trial, but had only intermediate incidence in the Chertsey irrigated trial. Conversely, Claire and Alberic were the most heavily infected cultivars in the Chertsey irrigated trial, but were only the fourth and sixth most infected cultivars at Lincoln. This lack of consistency could be due to genetic (host-pathogen) or environmental interactions and warrants investigation. Firstly, it is possible that some cultivars are more susceptible to some $R$. cerealis populations than to others, reflecting a gene-for-gene interaction.

It is also possible that relative cultivar resistance can be affected by environment. It is known that sowing date and soil moisture and temperature can affect sharp eyespot severity (Wiese 1987) and it is possible that such factors could differentially affect disease development amongst cultivars. Until these causes of variation between trials are resolved, it will be important to conduct cultivar testing at a range of sites over time to accurately assess relative cultivar resistance. The high level of sharp eyespot in some cultivars in some trials indicates that they have the potential to be heavily infected. Conversely, those cultivars that have low disease levels in all trials can reasonably be claimed to be resistant to the disease, although confirmation in further trials will be desirable.

As well as cultivar differences between trials, there were often large differences between plots of individual cultivars in the same trial. Such differences are probably due to the uneven distribution of soilborne inoculum within trials. It is a common practice to artificially inoculate sharp eyespot cultivar trials with one or more isolates of R. cerealis. While this will ensure that plants in each plot are exposed to pathogen inoculum, it does not ensure that they are exposed to the same level of inoculum. In the current trials, high disease incidence was recorded in some plots, in spite of reliance on natural inoculum. Adding inoculum equally to all plots may overwhelm the resistance of some cultivars in plots that already have a high level of natural inoculum. Further experiments comparing natural versus applied inoculum are planned in order to optimise assessment methods.

The other advantage of applying inoculum is that it ensures sufficient inoculum for disease expression. Two of the three trials had sufficient disease incidence to compare cultivars. The low-incidence dryland Chertsey trial was adjacent to the irrigated Chertsey trial and it is therefore more likely that soil moisture was responsible for differences in disease incidence than the levels of primary inoculum. However, inoculum differences cannot be ruled out, since the trials were adjacent, and irrigated/dryland treatments were not included within the trials for practical reasons.

Hollins \& Scott (1983a) assessed seedling and adult plant resistance to sharp eyespot in glasshouse tests. They detected differences between cultivars at both growth stages, but results for seedlings and adult plants were not correlated. However, results for adult plants in the glasshouse were comparable to field scores of adult plants. This difference in ranking between seedling and adult stages demonstrated that growth stage is important when assessing resistance to sharp eyespot.

The present study has revealed considerable variation in sharp eyespot resistance between currently grown New Zealand commercial wheat cultivars. Because yield losses due to sharp eyespot have been demonstrated to be negligible when disease incidence is below 10\% (Cromey et al. 2002), the most appropriate strategy for control of the disease is probably the avoidance of highly susceptible cultivars, especially in early autumn-sown crops amongst which disease incidence is usually greatest (M.G. Cromey, unpubl. data). Sharp eyespot susceptibility should therefore be considered by plant breeders during cultivar selection. While destructive sampling of plots will provide the most accurate differentiation of resistant and partially resistant cultivars, highly susceptible cultivars can easily be distinguished in situ during grainfill, as long as assessments are made in several plots and trials. 


\section{ACKNOWLEDGEMENTS}

The Chertsey trials were managed by Mr Bede McCloy. The Foundation for Arable Research (FAR) funded the establishment and maintenance of all trials. Sharp eyespot resistance research undertaken in these trials was funded by the New Zealand Foundation for Research, Science and Technology.

\section{REFERENCES}

Clarkson JDS, Cook RJ 1983. Effects of sharp eyespot on yield loss in winter wheat. Plant Pathology 32: 421-428.

Clulow M, Wale SJ 1984. Resistance of cultivars of wheat, barley and oats to sharp eyespot. Annals of Applied Biology 104 (Supplement, Tests of Agrochemicals and Cultivars, 5): 104-105.

Cromey MG, Butler RC, Boddington HJ, Moorhead AR 2002. Effects of sharp eyespot on yield of wheat (Triticum aestivum). New Zealand Journal of Crop and Horticultural Science 30: 9-17.

He W, Song Y, Zhang Z 1998. Evaluation of resistance of wheat cultivars to sharp eyespot. Crop Genetic Resources 39: 30-31.

Hollins TW, Scott PR 1983a. Sharp eyespot. Annual Report of the Plant Breeding Institute. Plant Breeding Institute, Cambridge, U.K. Pp. 99-100.

Hollins TW, Scott PR 1983b. Resistance of wheat cultivars to sharp eyespot caused by Rhizoctonia cerealis. Annals of Applied Biology 102 (Suppl.): 126-127.

Wiese MV 1987. Compendium of wheat diseases. Second edition. APS Press, St Paul, Minnesota.

Shi J, Wang Y, Chen H 2000. Screening techniques and evaluation of wheat resistance to sharp eyespot caused by Rhizoctonia cerealis. Acta Phytophylacica Sinica 27: 107-112. 